\title{
Irradiation of large area Mylar membrane and characterization of nuclear track filter
}

\author{
N K ACHARYA, P K YADAV, S WATE ${ }^{*}$, Y K VIJAY*, F SINGH ${ }^{\dagger}$ and D K AVASTHI \\ Department of Physics, University of Rajasthan, Jaipur 302 004, India \\ ${ }^{\dagger}$ Nuclear Science Centre, Aruna Asaf Ali Marg, New Delhi 110 067, India \\ ${ }^{\ddagger}$ Govt. Arts and Science College, Ratlam 457 001, India
}

MS received 10 April 2003; revised 30 August 2004

\begin{abstract}
Ion irradiation of $\mathrm{Si}^{8+}$ ion beam of $100 \mathrm{MeV}$ was scattered by a gold foil on a Mylar membrane of $25 \mu \mathrm{m}$ thickness in the form of film roll (width, $12.5 \mathrm{~cm}$ and length, $400 \mathrm{~cm}$ ) at the Nuclear Science Centre, New Delhi. The characterization of etched nuclear tracks was carried out by gas permeation measurements. The samples cut from the film roll of required size for permeability measurements were etched in a controlled manner in a constant temperature bath of $6 \mathrm{~N} \mathrm{NaOH}$ solution. The opening of the conical etched tracks was characterized by hydrogen gas permeation.
\end{abstract}

Keywords. Mylar roll; SHI irradiation; permeability; chemical etching.

\section{Introduction}

Nuclear track membranes from different polymers were developed by standard techniques (Chakarvarti and Vetter 1991; Shtanko et al 1999; Adla et al 2001). Such types of polymers are known as excellent track detectors. The track membranes have very narrow pore size distribution and low sorption ability, which leads to their application in gas and liquid filtration (Adla et al 2001). The matrix material i.e. type of the polymer, characterizes the physical and chemical properties of track membrane. For a special application of track membrane, it is essential to change physical and chemical properties of the track membrane (Adla et al 2001). In this regard the chemical etching of track membrane is applied for obtaining the desired size and shape of the tracks (Kumar and Prasad 2000).

Some polymers are less permeable to gases due to the small free volume available in the polymer matrix. When an ion slows down in the material it looses or stores most of its energy in areas away from the trajectory or just deexcites in time depending on the type of material. In insulators electronic excitation can induce extended defects along the ion path due to the secondary ionization (Mehta 1996). Many polymers are able to recover the track halo up to a certain limit of the order of a few nm i.e. Mylar or polyethylene terephthalate (PET). When heavy ion beam passes through PET several gases like $\mathrm{H}_{2}, \mathrm{CO}$ and $\mathrm{C}_{2} \mathrm{H}_{4}$ are evolved due to breaking of bonds and track dimension is estimated to be around $6 \mathrm{~nm}$ (Avasthi et al 1998).

\footnotetext{
*Author for correspondence
}

Atomic force microscopy (AFM), Fourier transform of infrared spectroscopy (FTIR) and small angle X-ray spectroscopy (SAXS) techniques are used to characterize the chemical and physical modifications. The SAXS can study the track core with a radius of $3-5 \mathrm{~nm}$, while the conventional processes occur in a larger halo (Escoubes et al 1995; Trautmann et al 1999). The chemical etching is a unique technique to enlarge the tracks produced by irradiation and the membranes are characterized by the gas permeation study. The penetrant migration processes in a polymer are closely related to the abundant free volume and to the defect density.

The aim of the work was to produce a large area track membrane modified by swift heavy ion irradiation.

In the present work, the roll of Mylar membrane having a dimension of $400 \mathrm{~cm} \times 12.5 \mathrm{~cm}$ and a thickness of $25 \mu \mathrm{m}$ was irradiated by $100 \mathrm{MeV} \mathrm{Si}^{8+}$ ion beam. The dose distribution was estimated throughout the roll by gas permeation measurements.

\section{Experimental}

\subsection{Irradiation and etching}

The chemical structure of the Mylar given in figure 1 has a density of $1.39 \mathrm{~g} / \mathrm{cm}^{3}$. The Mylar membrane used in the present study is commercially available. The roll of Mylar membrane was irradiated by $100 \mathrm{MeV} \mathrm{Si}^{8+}$ ion beam using the 15 UD Pelletron facility in the general purpose scattering chamber (GPSC) under high vacuum of $6.5 \times 10^{-6}$ torr at the Nuclear Science Centre, New Delhi. The ion beam was defocused and scattered by gold foil $(250 \mu \mathrm{g} /$ 
$\mathrm{cm}^{2}$ ), the corresponding energy loss $(\mathrm{d} E / \mathrm{d} X)_{\mathrm{e}}$ was $\sim 1 \mathrm{MeV}$ for $\mathrm{Si}$ ion. Consequently the average energy of scattered beam on roll was $\approx 99 \mathrm{MeV}$ as shown in figure 3 . The width of membrane roll was $12.5 \mathrm{~cm}$ and was kept $60 \mathrm{~cm}$ away from the scatterer. The surface barrier detector was kept inside the chamber at a certain angle ( 24 degree) to estimate the actual dose.

The roll was rotating continuously at a speed of $1 \mathrm{~mm} / \mathrm{s}$ during irradiation to avoid the non-uniformity as shown in figure 3 . The fluence of ion beam varied with the angle, however, defocused beam on the gold foil and further scattering might result into the uniform dose distributed along the membrane. The circular discs having diameter of $38 \mathrm{~mm}$ were cut along and across the central axis. These different discs were used to study the dose distribution by gas permeation.

The etching process was performed in $6 \mathrm{~N} \mathrm{NaOH}$ solution at a constant temperature of $60^{\circ} \mathrm{C}$. The etchant was changed periodically to keep the same concentration.

\subsection{Characterization by gas permeability}

The irradiated roll was characterized by hydrogen gas permeability. The permeability of any penetrant through the membrane can be understood by solution diffusion model (Dhingra 1997). The permeation process occurred in three stages, viz. sorption, diffusion and desorption. The sorption of gas molecules occurred at the upstream side of the membranes. Because of concentration gradient, the molecules diffused across the membrane before finally desorbing on the downstream side of the mem-<smiles>COC(=O)c1ccc(C(=O)OCC(C)C)cc1</smiles>

Figure 1. Repeating unit of polyethylene terephthalate (PET) or Mylar.

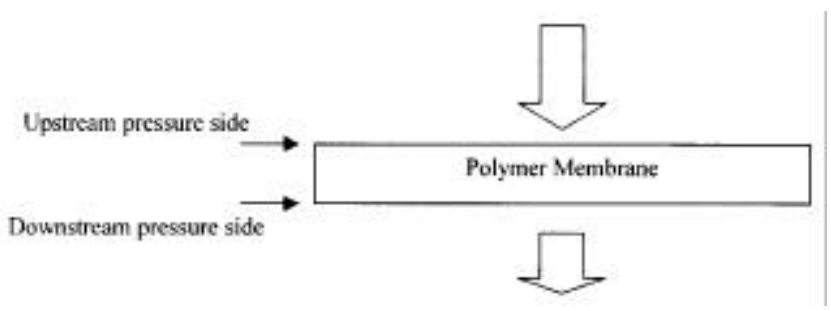

Figure 2. Schematic of permeation process through dense membrane. brane as shown in figure 2 . The permeability was defined as the product of solubility and diffusivity coefficients and permeability process obeys the Henry's and Fick's law (Remmert et al 1995). The permeability was measured by the formula

$$
P=(J \times l) / \Delta p,
$$

where $J$ is the flux that penetrates through the membrane, $l$ the thickness of the membrane and $\Delta p$ the pressure difference across the membrane.

We have measured permeability using the permeability cell. The schematic diagram and description of the cell are given elsewhere (Vijay et al 2002). The permeability is often expressed in barrer $\left(1\right.$ barrer $=10^{-10}\left[\left\{\mathrm{~cm}^{3}(\mathrm{STP})\right.\right.$ $\mathrm{cm} / \mathrm{cm}^{2}$.s.cm-Hg\}].

\section{Results and discussion}

Polyethylene terephthalate (PET) or Mylar has higher resistance to irradiation as compared to the other glassy polymer i.e. polycarbonate, due to its complex chemical structure or strong binding. The Mylar is very less permeable for hydrogen. To improve its permeability, the tracks generated during irradiation can be enlarged by employing suitable chemical treatment. The permeability depends on the free volume available in between the polymer chains (Barbari et al 1988). However, irradiation increases the free volume due to chain scissioning, consequently the permeability increases. The permeability of hydrogen for untreated PET membrane is found to be $0 \cdot 045$ barrer.

The roll of Mylar is exposed and several discs are cut to measure the gas permeability. The permeability of hydrogen through PET membrane measured for several discs is found to increase 19 times after irradiation, 22 times after 15 min etching of irradiated sample and 26

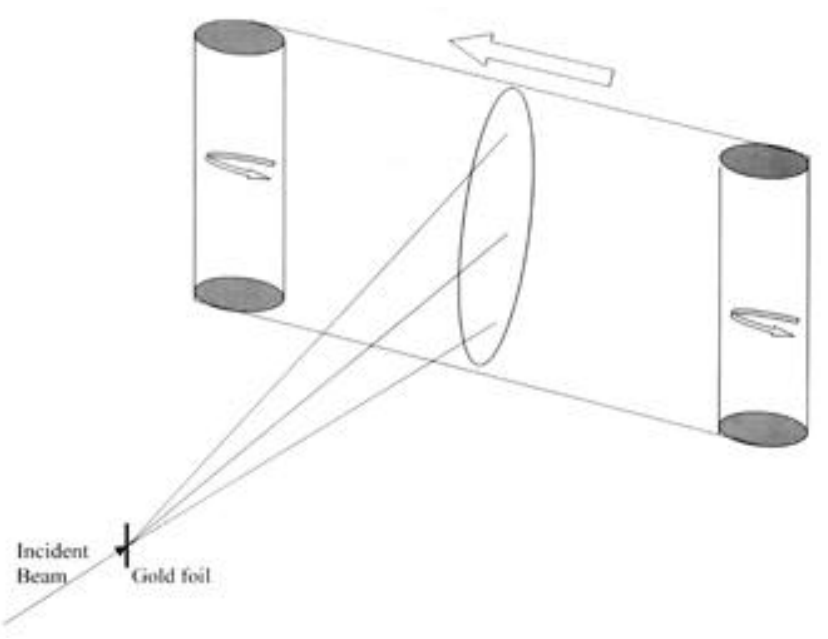

Figure 3. Schematic of large area Mylar membrane irradiation. 
Table 1. Permeability for the samples cut from the first section.

\begin{tabular}{lcccc}
\hline S1. no. & $\begin{array}{c}\text { Sample } \\
\text { (increased factor) }\end{array}$ & $\begin{array}{c}\text { As irradiated } \\
\text { (increased factor) }\end{array}$ & $\begin{array}{c}\text { Irradiated and 15 min } \\
\text { etched (increased factor) }\end{array}$ & $\begin{array}{c}\text { Irradiated and 30 min } \\
\text { etched (increased factor) }\end{array}$ \\
\hline 1. & Sample A & 19 & 21 & 26 \\
2. & Sample B & 19 & 22 & 26 \\
3. & Sample C & 19 & 22 & 26 \\
\hline
\end{tabular}

Table 2. Permeability for the samples cut from the second section.

\begin{tabular}{lcccc}
\hline S1. no. & $\begin{array}{c}\text { Sample } \\
\text { (increased factor) }\end{array}$ & $\begin{array}{c}\text { As irradiated } \\
\text { (increased factor) }\end{array}$ & $\begin{array}{c}\text { Irradiated and 15 min } \\
\text { etched (increased factor) }\end{array}$ & $\begin{array}{c}\text { Irradiated and 30 min } \\
\text { etched (increased factor) }\end{array}$ \\
\hline 1. & Sample A & 19 & 24 & 26 \\
2. & Sample B & 19 & 24 & 26 \\
3. & Sample C & 19 & 22 & 26 \\
\hline
\end{tabular}

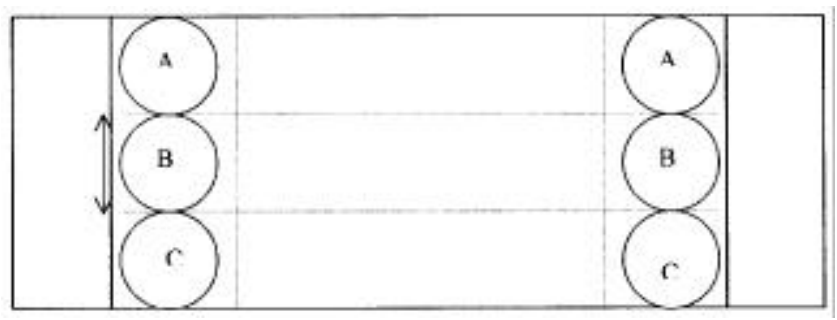

Figure 4. Various samples cut from different parts of Mylar roll.

times after 30 min etching of irradiated sample than that of untreated sample. The permeability data is almost similar or within the error limit as shown in tables 1 and 2 . However, according to Rutherford scattering the dose varies with the angle of incidence $(\theta)$ as below:

$$
N(\theta) \propto \operatorname{cosec}^{4}(\theta / 2) .
$$

But at smaller angle, the dose distribution is almost the same. In the present experiment, the energy uniformly falls on roll, and all other parameters remain the same during exposure.

The discs were cut from various parts of the roll e.g. A, $\mathrm{B}$ and $\mathrm{C}$, as shown in figure 4 . The dose variation of these samples was of the order of 10 , so that the permeability of hydrogen for Mylar was found to be within error limit. Also, Mylar has the property to recover the damaged area during irradiation. It is assumed that the radial extension of the damaged region may fluctuate along the entire length of the ion track in PET membrane (Eyal and Gassan 1999). The data shows that the tracks of reduced density are formed and the destroyed core of the ion tracks also partially recovers the density difference to the surrounding region and becomes less pronounced (Steckenreiter et al 1995). So the permeability of hydrogen is found to be same for entire length of the roll. Etching of irradiated sample increased the permeability but increased factor remains same for different parts of the roll as shown in tables 1 and 2 .

\section{Conclusion}

From the above results we can conclude that the large area Mylar membrane has almost same permeability for hydrogen even at different etching times for the samples taken from different parts of the long roll.

\section{Acknowledgements}

The authors are thankful to the Nuclear Science Centre, New Delhi and IUC, Kolkata, for providing financial assistance.

\section{References}

Adla A, Buschmann V, Fuess H and Trautmann C 2001 Nucl. Instrum. \& Meth. Phys. Res. $\mathbf{B} 185210$

Avasthi D K, Singh J P, Biswas A and Bose S K 1998 Nucl. Instrum. \& Meth. Phys. Res. B146 504

Barbari T A, Koros W J and Paul D R 1988 J. Polym. Sci.: Polym. Phys. 26709

Chakarvarti S K and Vetter J 1991 Nucl. Instrum. \& Meth. Phys. Res. B62 109

Dhingra S S 1997 Mixed gas transport study through polymeric membrane: A noval technique, Ph.D. Thesis, Virginia Polytechnic Institute and State University, Blacksburg, Virginia

Escoubes M, Dolveck J Y, Davenas J, Xu X L and Boiteux G 1995 Nucl. Instrum. \& Meth. Phys. Res. B105 130

Eyal Yehuda and Gassan Khatib 1999 Nucl. Instrum. \& Meth. Phys. Res. B156 183

Kumar Ashwani and Prasad Rajendra 2000 Nucl. Instrum. \& Meth. Phys. Res. B168 411 
Mehta G K 1996 Nucl. Instrum. \& Meth. Phys. Res. A382 335

Remmert G, Eyal Y, Fischer B E and Spohr R 1995 Nucl. Instrum. \& Meth. Phys. Res. B105 197

Shtanko N I, Kabanov V Ya, Apel P Yu and Yoshida M 1999 Nucl. Instrum. \& Meth. Phys. Res. B151 416
Steckenreiter T, Fuess H, Stamm M and Trautmann C 1995 Nucl. Instrum. \& Meth. Phys. Res. B105 200

Trautmann C, Schwartz K and Steckenreiter T 1999 Nucl. Instrum. \& Meth. Phys. Res. B156 162

Vijay Y K, Wate S, Acharya N K and Garg J C 2002 Int. J. Hydrogen Energy 27905 